\title{
tiv BIOENG
}

\section{QUALIDADE DE GRÃOS DE SOJA ARMAZENADOS EM BAIXAS TEMPERATURAS}

\author{
P. C. Coradi ; L. V. Milane; L. J. Camilo; R. L. F. Prado; T. C. \\ Fernandes
}

UFMS - Univ Federal do Mato Grosso do Sul, Campus Universitário de Chapadão do Sul, MS, Brasil

Article history: Received 18 July 2015; Received in revised form 10 August 2015; Accepted 12 August 2015; Available online 30 September 2015.

\section{RESUMO}

Objetivou-se com este estudo avaliar a qualidade de grãos de soja armazenada durante seis meses em ambiente com temperaturas baixas e em diferentes embalagens. $O$ delineamento experimental utilizado foi inteiramente casualizado, fatorial $(2 \times 3 \times 2)$, sendo dois tipos de embalagens (sacos de papel permeável e sacos de plástico de polietileno), três temperaturas de acondicionamento $\left(3,10\right.$ e $\left.23{ }^{\circ} \mathrm{C}\right)$ e dois tempos de avaliação (zero e seis meses). $\mathrm{O}$ aumento do tempo de armazenamento reduziu à qualidade dos grãos de soja, independentemente das condições de armazenamento e embalagem. $\mathrm{O}$ armazenamento em embalagem permeável afetou mais a qualidade dos grãos de soja. A temperatura de armazenamento de $23{ }^{\circ} \mathrm{C}$ foi a que mais alterou negativamente a qualidade dos grãos de soja. $\mathrm{O}$ armazenamento na temperatura do ar de $3{ }^{\circ} \mathrm{C}$ foi mais favorável para a qualidade dos grãos de soja, embora alguns resultados de qualidade foram iguais, com o armazenamento na temperatura de $10{ }^{\circ} \mathrm{C}$. Concluiu-se que, o resfriamento artificial do ambiente de armazenamento para temperaturas inferiores a $10{ }^{\circ} \mathrm{C}$ pode ser a melhor alternativa para preservar a qualidade dos grãos armazenados. As embalagens impermeabilizadas, para as mesmas condições médias de temperatura e umidade relativa do ar de armazenagem podem contribuir para minimizar perdas em grãos de soja, em comparação com embalagens permeáveis, considerando-se os atributos qualitativos analisados.

Palavras-chave: Glycine max (L.) Merril, indústria, pós-colheita.

\section{QUALITY OF SOYBEAN GRAINS STORED IN LOW TEMPERATURES}

\begin{abstract}
The aim of this study was to evaluate the quality of soybeans stored for six months in an environment with low temperatures and in different packaging. The experimental design was completely randomized, factorial $(2 \times 3 \times 2)$, two types of packaging (permeable paper bags and polyethylene plastic bags) three packaging temperatures $\left(3,10\right.$, and $\left.23{ }^{\circ} \mathrm{C}\right)$ and two times of evaluation (zero and six months). The increased storage time reduced quality of soybeans, regardless of storage conditions and packaging. Storage in permeable packaging affected more the quality of soybeans. The storage temperature of $23^{\circ} \mathrm{C}$ was the most negatively alter

"paulocoradi@yahoo.com.br
\end{abstract}


the quality of soybeans. Storage in air temperature of $3{ }^{\circ} \mathrm{C}$ was most favorable for the quality of soybeans, although some quality results were similar, with storage at $10{ }^{\circ} \mathrm{C}$. In conclusion, the artificial cooling of the storage environment to temperatures below $10^{\circ} \mathrm{C}$ can be the best alternative to preserve the quality of stored grain. The impermeable packaging for the same average conditions of temperature and relative humidity of the air storage can help to minimize losses in soybeans, in comparison with permeable packings, considering the quality parameters analyzed.

Keywords: Glycine max (L.) Merril, industry, post-harvest.

\section{INTRODUÇÃO}

A soja é a principal cultura oleaginosa produzida no mundo e tem lugar de destaque como fonte de proteína para seres humanos e animais domésticos (CONAB, 2015). Representa aproximadamente $90 \%$ da produção de óleo vegetal e mais de $80 \%$ da produção de biodiesel no Brasil. Na fase de póscolheita, a leguminosa passa por diferentes operações unitárias de pré-processamento como limpeza, secagem, armazenamento e classificação qualitativa. Muitas dessas operações podem reduzir a qualidade dos grãos e prejudicá-los na conservação (ZIEGLER, 2014). Normalmente, os grãos de soja são armazenados em estruturas de grande porte, mas com o aumento da produção mundial de grãos existe uma preocupação, pois a capacidade estática de armazenagem de grãos já está em déficit em relação à produção, necessitando de novos investimentos.

As perdas de qualidade dos grãos, depois da colheita, ocorrem principalmente por causa de infestações por insetos-praga e degradação por infecções fúngicas. A respiração e a degradação progressiva da qualidade nutricional dos grãos contribuem com uma proporção, nas perdas totais de grãos, que ocorrem durante o armazenamento (ELIAS, 2009; PEREIRA et al., 2011). Para CARDOSO et al. (2012), o processo de deterioração é inevitável, mas pode ser minimizado, dependendo das condições de armazenamento e das características dos grãos.
Para industrializar os grãos, a fim de produzir biodiesel e óleos comestíveis, necessita de armazená-los durante períodos prolongados de tempo. As técnicas tradicionais existentes de armazenagem não garantem a conservação dos grãos durante o armazenamento, mesmo para médio intervalo de tempo. O conhecimento das características físicas e químicas dos grãos em questão pode ajudar a minimizar estes problemas por meio de uma gestão adequada (ELIAS, 2009; CORADI et al., 2014a). Os fatores que mais influenciam a taxa de degradação dos grãos são a temperatura e a umidade. De acordo com LACERDA FILHO et al. (2000), os teores de água dos grãos têm maior interferência do que os outros fatores, incluindo a temperatura.

Entre os fatores externos que mais afetam o ecossistema da massa de grãos são temperatura e umidade relativa do ar intergranular que prevalece no local de armazenamento (SMANIOTTO et al., 2014). A umidade relativa do ar intergranular aliada a temperatura do ambiente tem forte influência sobre a qualidade dos grãos armazenados (RANI et al., 2013). A variação da temperatura ambiente pode ser extrema, entre 0 e 40 ${ }^{\circ} \mathrm{C}$, valores suficientes e favoráveis para infestações de insetos, contaminação por fungos e deterioração da massa de grãos armazenada.

O efeito combinado da umidade relativa do ar intergranular e da temperatura de armazenamento determinam a atividade de todos os 
componentes bióticos do sistema, que levam a um armazenamento seguro ou a perdas de produto (SOARES JÚNIOR et al., 2008; ELIAS et al., 2010).

A degradação dos grãos durante o armazenamento pode ser indicada por meio da observação de algumas mudanças nos parâmetros de qualidade, incluindo $\mathrm{o}$ aumento dos níveis de acidez e peróxidos, no escurecimento do grão e redução dos teores de óleo da soja. Segundo ALENCAR et al. (2009) durante o armazenamento, a fração de proteína pode ser submetida a várias reações que causam a desaminação de aminoácidos, ácidos orgânicos e compostos de amoníaco, formando a descarboxilação com a formação de aminas, causando deterioração do grão, dando odor forte e desagradável, escurecimento.

\section{MATERIAL E MÉTODOS}

O trabalho experimental foi realizado na Universidade Federal de Mato Grosso do Sul (UFMS), Campus de Chapadão do Sul (CPCS), Laboratório de Pós-colheita de Grãos. Os grãos de soja foram colhidos de forma aleatória, ou seja, em diferentes pontos da massa de grãos, em seguida, os grãos foram submetidos ao processo de limpeza, utilizando máquina de ar e peneira. Posteriormente, os grãos foram secados em um secador contínuo de fluxos mistos, com capacidade nominal de 50 ton $\mathrm{h}^{-1}$. A temperatura do ar de secagem foi de $90{ }^{\circ} \mathrm{C}$. Foram realizados três testes de secagem e durante os testes foram colhidas amostras para medição dos teores de água. A secagem foi realizada até os grãos atingirem os teores de água de $11,5 \%$ (b.u.), recomendada para armazenagem. A temperatura e a umidade relativa do ar foram monitoradas durante todo $\mathrm{o}$ processo, com o auxílio de um psicrômetro. Durante a secagem foi feito o acompanhamento da temperatura da massa de grãos, utilizando os sensores termopares
As características de conservabilidade dos grãos durante $o$ armazenamento é diretamente influenciada pela sua qualidade inicial, pelas suas características físicas, teor de água e temperatura da massa de grãos e do ar no ambiente de armazenamento. Os grãos armazenados permanecem respirando e, dependendo das condições de armazenamento, a atividade metabólica pode ser reduzida ou acelerada, desencadeando uma série de reações bioquímicas que afetam quantitativamente e qualitativamente os componentes dos grãos, bem como, as suas propriedades tecnológicas. Assim, objetivou-se neste estudo avaliar a qualidade de grãos de soja armazenadas durante seis meses em ambiente com temperaturas baixas $(3,10 \mathrm{e}$ $23{ }^{\circ} \mathrm{C}$ ) e em diferentes embalagens (permeável e impermeável).

instalados no próprio secador, na câmara de secagem.

Após cada teste de secagem, dez quilogramas de amostras de grãos de soja a granel foram coletados aleatoriamente. A coleta foi realizada com auxílio de um calador de grãos manual. Então, os grãos de soja foram armazenados, em três ambientes controlados, em sala climatizada com temperatura de $23{ }^{\circ} \mathrm{C}$ e umidade relativa de $80 \%$, em câmaras climáticas B.O.D com temperatura de $10{ }^{\circ} \mathrm{C}$ e umidade relativa de $60 \%$, freezers com temperatura de $3{ }^{\circ} \mathrm{C}$ e umidade relativa de 40\%. Para todas as temperaturas de armazenamento foram utilizados dois tipos de embalagens (saco de papel permeável e saco de plástico polietileno impermeável). As amostras ficaram armazenadas durante seis meses e neste período, fez-se avaliações das propriedades físicas e qualidade físico-química, antes e após o armazenamento (tempos zero e seis meses). Durante o armazenamento monitorou-se a temperatura da massa de grãos com auxílio de termopares do tipo J. 
Durante o tempo de armazenamento, monitorou-se a temperatura e a umidade relativa do ambiente, por meio de um psicrômetro.

O teor de água de grãos (\% b.u.) foi determinado por pesagem de $15 \mathrm{~g}$ de amostra. Em seguida, as amostras foram colocadas em estufa com convecção forçada de ar e aquecimento regulado a $103 \pm 1{ }^{\circ} \mathrm{C}$ durante $24 \mathrm{~h}$, de acordo com as recomendações do BRASIL (2009). A análise das propriedades físicas dos grãos de soja foi realizada de acordo com a metodologia descrita por MOHSENIN (1986), e a determinação de grãos ardidos, de acordo com as normas de classificação física de grãos descrita por BRASIL (2007). O teste de condutividade elétrica

\section{RESULTADOS E DISCUSSÃO}

A análise de variância indicou que
houve interação significativa entre
embalagens, tempo de armazenamento e
temperatura do ambiente de
armazenamento $(\mathrm{p}<0,05)$. Os resultados
das avaliações das propriedades físicas dos
grãos de soja armazenadas, estão
apresentados na Tabela 1.
As alterações nas características
físicas dos grãos de soja ocorreram
principalmente nas embalagens
permeáveis. A embalagem de papel
permeável permite trocas de vapor de água
entre os grãos e o ar ambiente de
armazenamento, isto implica em gradientes
de pressão de vapor que se estabelece entre
os grãos e o ar ambiente, em função da
temperatura, da umidade relativa do ar e
dos teores de água dos grãos.
O aumento dos teores de água com
o aumento do tempo de armazenamento

foi realizado nos grãos de soja, de acordo com a metodologia descrita por VIEIRA \& KRZYZANOWSKI (1999). A análise do índice de acidez, a porcentagem de proteína bruta e de cinzas foi feito de acordo com a metodologia descrita por segundo AOAC (2000).

$\mathrm{O}$ delineamento experimental foi inteiramente casualizado, fatorial $(3 \times 2 \times 2)$, três temperaturas de armazenamento $(3,10$ e $23{ }^{\circ} \mathrm{C}$ ), dois tipos de embalagens (sacos de papel permeáveis e sacos de plástico polietileno impermeáveis), dois tempos de armazenamento (zero e seis meses). Para avaliação dos resultados foram feitas análises de variância e testes de médias comparadas pelo teste de Tukey, a 5\% de probabilidade.

afetou diretamente as propriedades físicas dos grãos. Comparando-se os tipos de embalagens, verificou-se que as características físicas iniciais dos grãos, quando armazenados em embalagens impermeáveis foram menos alterados. As condições de armazenamento influenciaram na redução dos teores de água dos grãos de 10 para $9 \%$ (b.u.), nas temperaturas de armazenamento de 3 e 10 ${ }^{\circ} \mathrm{C}$. Essas alterações ocorreram em função da baixa umidade relativa do ar (30 e 40\% de UR, respectivamente), no ambiente de armazenamento, enquanto que, os grãos armazenados na temperatura do ar de 23 ${ }^{\circ} \mathrm{C}$, observou-se aumento dos teores de água de 10 para $11 \%$ (b.u.), devido à alta umidade relativa do ar ambiente (UR 80\%) 
Tabela 1. Qualidade física de grãos de soja armazenados em diferentes temperaturas do ar de armazenamento e embalagens

\begin{tabular}{|c|c|c|c|c|c|c|c|}
\hline \multicolumn{2}{|c|}{ Condicões armazenamento } & \multicolumn{2}{|c|}{$10^{0} \mathrm{C}$} & \multicolumn{2}{|c|}{$23{ }^{0} \mathrm{C}$} & \multicolumn{2}{|c|}{$3{ }^{0} \mathrm{C}$} \\
\hline Avaliações & $\begin{array}{l}\text { Tempo } \\
\text { (meses) }\end{array}$ & $\mathrm{P}$ & I & $\mathrm{P}$ & I & $\mathrm{P}$ & I \\
\hline \multirow{2}{*}{$\begin{array}{l}\text { Teor de água } \\
\text { (\% b.u.) }\end{array}$} & 0 & $10,31 \mathrm{Aa}$ & $10,31 \mathrm{Ba}$ & $10,31 \mathrm{Ba}$ & $10,31 \mathrm{Ba}$ & $10,31 \mathrm{Aa}$ & $10,31 \mathrm{Aa}$ \\
\hline & 6 & $9,20 \mathrm{Bb}$ & $11,0 \mathrm{Aa}$ & $11,20 \mathrm{Ab}$ & $12,00 \mathrm{Aa}$ & $9,90 \mathrm{Bb}$ & $10,50 \mathrm{Aa}$ \\
\hline \multirow{2}{*}{$\begin{array}{l}\text { Massa específica } \\
\left(\mathrm{kg} \mathrm{m}^{-3}\right)\end{array}$} & 0 & $730 \mathrm{Aa}$ & $730 \mathrm{Aa}$ & $730 \mathrm{Aa}$ & $750 \mathrm{Aa}$ & $710 \mathrm{Aa}$ & $720 \mathrm{Aa}$ \\
\hline & 6 & $620 \mathrm{Ba}$ & $620 \mathrm{Ba}$ & $620 \mathrm{Ba}$ & $620 \mathrm{Ba}$ & $620 \mathrm{Ba}$ & $620 \mathrm{Ba}$ \\
\hline \multirow{2}{*}{$\begin{array}{l}\text { Comprimento } \\
\text { (mm) }\end{array}$} & 0 & $606 \mathrm{Ba}$ & $606 \mathrm{Ba}$ & $606 \mathrm{Aa}$ & $606 \mathrm{Aa}$ & $606 \mathrm{Ba}$ & $606 \mathrm{Ba}$ \\
\hline & 6 & $6,62 \mathrm{Aa}$ & $6,66 \mathrm{Aa}$ & $6,09 \mathrm{Aa}$ & $6,02 \mathrm{Aa}$ & $6,66 \mathrm{Aa}$ & $6,64 \mathrm{Aa}$ \\
\hline \multirow{2}{*}{$\begin{array}{c}\text { Largura } \\
(\mathrm{mm})\end{array}$} & 0 & $6,72 \mathrm{Aa}$ & $6,72 \mathrm{Aa}$ & $6,72 \mathrm{Aa}$ & $6,72 \mathrm{Aa}$ & $6,72 \mathrm{Aa}$ & $6,72 \mathrm{Aa}$ \\
\hline & 6 & $6,05 \mathrm{Ba}$ & $6,13 \mathrm{Ba}$ & $6,71 \mathrm{Aa}$ & $6,61 \mathrm{Ab}$ & $6,05 \mathrm{Ba}$ & $6,08 \mathrm{Ba}$ \\
\hline \multirow{2}{*}{$\begin{array}{c}\text { Espessura } \\
(\mathrm{mm})\end{array}$} & 0 & $5,33 \mathrm{Aa}$ & $5,33 \mathrm{Ba}$ & $5,33 \mathrm{Ba}$ & $5,33 \mathrm{Aa}$ & $5,33 \mathrm{Ba}$ & $5,33 \mathrm{Ba}$ \\
\hline & 6 & $5,38 \mathrm{Ab}$ & $5,47 \mathrm{Aa}$ & $5,40 \mathrm{Aa}$ & $5,30 \mathrm{Ab}$ & $5,40 \mathrm{Aa}$ & $5,44 \mathrm{Aa}$ \\
\hline \multirow{2}{*}{$\begin{array}{l}\text { Volume } \\
\left(\mathrm{mm}^{3}\right)\end{array}$} & 0 & $114 \mathrm{Aa}$ & $114 \mathrm{Ba}$ & $114 \mathrm{Ba}$ & $114 \mathrm{Aa}$ & $114 \mathrm{Aa}$ & $114 \mathrm{Aa}$ \\
\hline & 6 & $113 \mathrm{Ab}$ & $117 \mathrm{Aa}$ & $116 \mathrm{Aa}$ & $111 \mathrm{Bb}$ & $114 \mathrm{Aa}$ & $115 \mathrm{Aa}$ \\
\hline \multirow{2}{*}{$\begin{array}{c}\text { Porosidade } \\
(\%)\end{array}$} & 0 & $35,87 \mathrm{Ba}$ & $35,87 \mathrm{Ba}$ & $35,87 \mathrm{Ba}$ & $35,87 \mathrm{Ba}$ & $35,87 \mathrm{Ba}$ & $35,87 \mathrm{Ba}$ \\
\hline & 6 & $38,48 \mathrm{Aa}$ & $39,15 \mathrm{Aa}$ & $38,62 \mathrm{Aa}$ & $38,47 \mathrm{Aa}$ & $39,43 \mathrm{Aa}$ & $38,81 \mathrm{Aa}$ \\
\hline \multirow[t]{2}{*}{ Esfericidade } & 0 & $0,99 \mathrm{Aa}$ & $0,99 \mathrm{Aa}$ & $0,99 \mathrm{Aa}$ & $0,99 \mathrm{Aa}$ & $0,99 \mathrm{Aa}$ & $0,99 \mathrm{Aa}$ \\
\hline & 6 & $0,90 \mathrm{Ba}$ & $0,91 \mathrm{Ba}$ & $0,99 \mathrm{Aa}$ & $0,98 \mathrm{Aa}$ & $0,90 \mathrm{Ba}$ & $0,91 \mathrm{Ba}$ \\
\hline \multirow[t]{2}{*}{ Circularidade } & 0 & $0,68 \mathrm{Ba}$ & $0,68 \mathrm{Ba}$ & $0,68 \mathrm{Ba}$ & $0,68 \mathrm{Ba}$ & $0,68 \mathrm{Aa}$ & $0,68 \mathrm{Aa}$ \\
\hline & 6 & $0,80 \mathrm{Aa}$ & $0,71 \mathrm{Ab}$ & $0,82 \mathrm{Aa}$ & $0,77 \mathrm{Aa}$ & $0,64 \mathrm{Ab}$ & $0,68 \mathrm{Aa}$ \\
\hline Grãos & 0 & $0,00 \mathrm{Ba}$ & $0,00 \mathrm{Ba}$ & $0,00 \mathrm{Ba}$ & $0,00 \mathrm{Ba}$ & $0,00 \mathrm{Ba}$ & $0,00 \mathrm{Ba}$ \\
\hline $\operatorname{ardidos}(\%)$ & 6 & $1,07 \mathrm{Aa}$ & $0,78 \mathrm{Ab}$ & $1,68 \mathrm{Aa}$ & $1,70 \mathrm{Aa}$ & $2,19 \mathrm{Aa}$ & $1,32 \mathrm{Ab}$ \\
\hline
\end{tabular}

Médias seguidas pela mesma letra maiúscula na coluna e letra minúscula na linha não é significativo a 5\% de probabilidade, P - Permeável, I - Impermeável.

KONG et al. (2008), analisando o armazenamento da soja a diferentes temperaturas e umidades relativas, observou aumento do teor de água dos grãos quando armazenados na temperatura de $40{ }^{\circ} \mathrm{C}$ e umidade relativa de $80 \%$, enquanto a umidade relativa do ar em $60 \%$ e temperatura de $40{ }^{\circ} \mathrm{C}$ manteve os grãos armazenados com teores de água acima de $13 \%$, entrando em equilíbrio higroscópico somente após dez meses, com teores de água de aproximadamente $8 \%$ (b.u.).

Observou-se, na Tabela 1, que os valores de massa específica aparente aumentou, enquanto que a porosidade diminuiu com o aumento do teor de água dos grãos armazenados, ao longo do tempo. A porosidade da massa de grãos é uma característica física importante em várias operações unitárias de pós-colheita, entre outras, pode ser mencionada à secagem, a aeração e o resfriamento artificial em função da pressão estática do ar ao passar através da massa de grãos (ALENCAR et al., 2009). RESENDE et al.
(2008) observaram que a porosidade da massa de grãos de soja aumenta, com o aumento do teor de água. RIBEIRO et al. (2005) utilizaram grãos de soja colhida com teores de água da ordem de $45 \%$ (b.u.) e relataram um aumento na massa específica aparente, com a redução dos teores de água. Os mesmos autores também observaram que a porosidade diminuiu linearmente de 44,7 para $41,1 \%$ com a redução do teor de água de $31 \%$ para $15 \%$ (b.u.). ALENCAR et al. (2009) observaram redução da massa específica de grãos de soja durante o armazenamento com teor de água de $14,8 \%$ e $40{ }^{\circ} \mathrm{C}$ de temperatura no ar ambiente, atribuindo este acontecimento em função da atividade metabólica dos grãos, associadas ao desenvolvimento de fungos e deterioração dos grãos.

A circularidade e a esfericidade dos grãos também variaram de acordo com o tipo de embalagem e com as condições de temperatura e umidade relativa do ar, durante $o$ armazenamento. Os grãos 
armazenados com temperaturas do ar de 23 ${ }^{\circ} \mathrm{C}$, UR de $80 \%$ e nas embalagens permeáveis, durante seis meses, tiveram aumento da circularidade e esfericidade dos grãos, enquanto que, os grãos armazenados com temperaturas abaixo de $10{ }^{\circ} \mathrm{C}$ e UR de $60 \%$ não sofreram alterações.

Verifica-se, na Tabela 1, que o comprimento, a largura, a espessura e o volume dos grãos sofreram alterações em função da redução do teor de água, nas condições de armazenamento com diferentes temperaturas e umidades relativas do ar. Nas temperaturas de 3 e 10 ${ }^{\circ} \mathrm{C}$ observou-se que o comprimento e a espessura dos grãos aumentaram, enquanto que, a largura diminuiu ao longo do tempo de seis meses, por outro lado, na temperatura de $23{ }^{\circ} \mathrm{C}$ não se observou diferenças. O tipo de embalagem não influenciou nas dimensões dos grãos. Em relação ao volume dos grãos, as maiores alterações ocorreram para as embalagens impermeáveis e na condição de armazenamento, com temperatura do ar de $23{ }^{\circ} \mathrm{C}$ e UR de $80 \%$, quando os grãos sofreram redução de volume, com $\mathrm{o}$ aumento do tempo de armazenamento. Os grãos armazenados em embalagens permeáveis, nas mesmas condições, sofreram perda de qualidade com o aumento de volume.

Em relação aos grãos ardidos, verificou-se que houve um aumento de percentual com o aumento do tempo de armazenamento. Foram observadas perdas mais elevadas de qualidade nas condições de armazenamento com temperatura de 23 ${ }^{\circ} \mathrm{C}$ e embalagem permeável. Este fato pode ser explicável, uma vez que, a tendência ao longo do tempo os grãos sofreram fermentação com o ganho de água do ambiente, tornando-se rançoso, e consequentemente ardidos.

Aos seis meses de armazenamento, para temperatura do ar de $23{ }^{\circ} \mathrm{C}$ observouse maior deterioração da massa de grãos, medida pelo teste de condutividade elétrica, especialmente nos grãos armazenados em embalagem permeável (Figura 1). A condutividade elétrica quantifica a lixiviação de substâncias ionizantes, que ocorre nos grãos em função dos danos mecânicos e, ou térmicos causados na estrutura celular (CORADI et al., 2014b). Observou-se, que houve aumento da deterioração dos grãos, pelo teste de condutividade elétrica, quando armazenados com $23{ }^{\circ} \mathrm{C}$. Para as condições de armazenamento de temperatura de 3 e $10{ }^{\circ} \mathrm{C}$ e embalagem impermeável, não houve diferenças significativas no teste de condutividade elétrica. SMANIOTTO et al. (2014) avaliaram a qualidade fisiológica de soja durante $\mathrm{o}$ armazenamento $\mathrm{e}$ descobriram que na temperatura de $20{ }^{\circ} \mathrm{C}$, os grãos se mantiveram com melhor qualidade, em função do teste de condutividade elétrica, comparado com o grão armazenado em temperaturas mais altas, com os mesmos teores de água. 

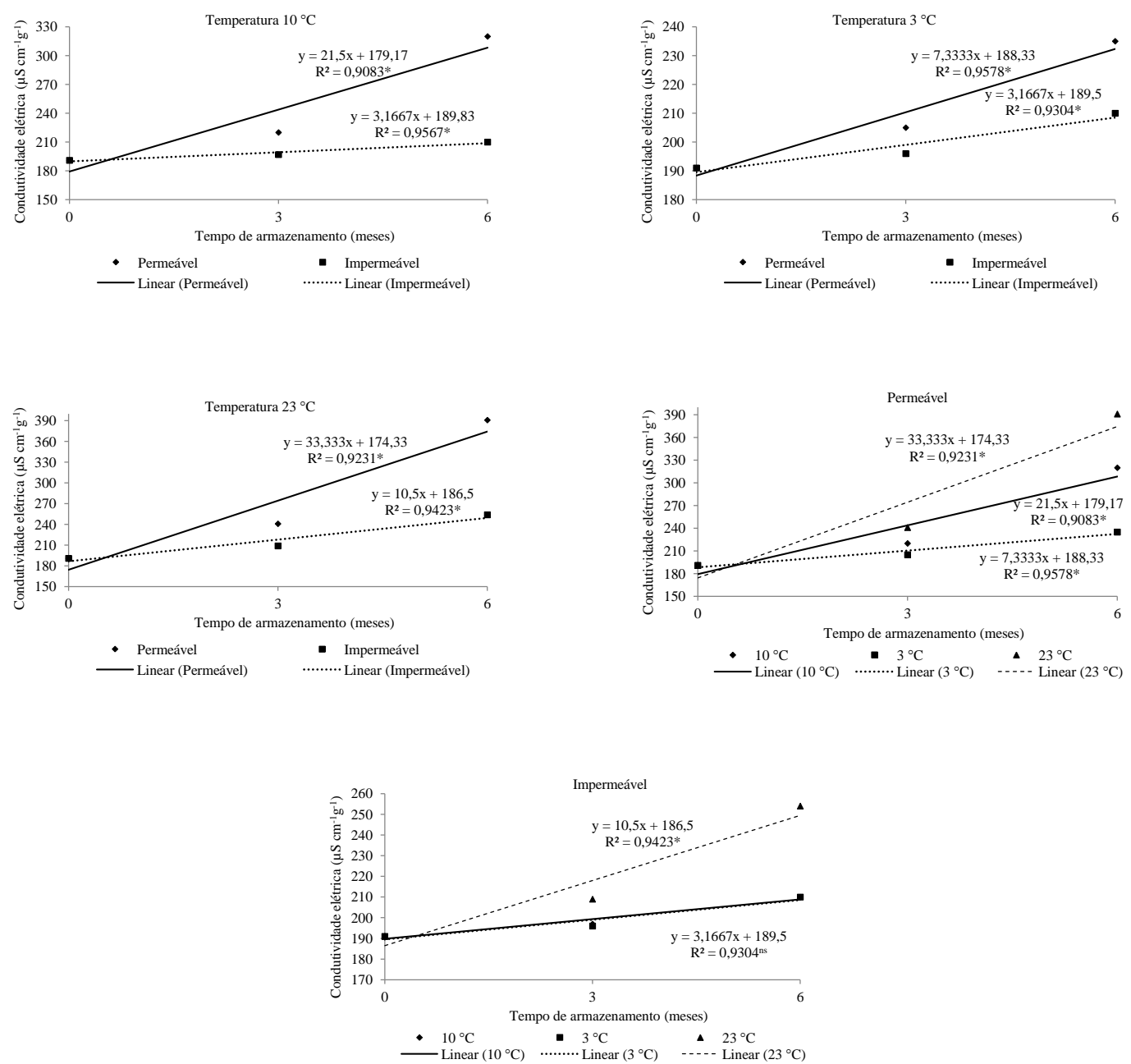

Figura 1. Avaliação da condutividade elétrica $\left(\mu \mathrm{S} \mathrm{cm}^{-1} \mathrm{~g}^{-1}\right)$ em grãos de soja armazenados em diferentes temperaturas do ar e embalagens, ao longo de seis meses. *Significativo $5 \%$ de probabilidade, ${ }^{\text {ns }}$ Não Significativo.

Durante o período de armazenamento, verificou-se que a porcentagem de extrato etéreo reduziu, independentemente das condições de temperatura do ar de armazenamento e do tipo de embalagem. Observou-se que, os efeitos foram negativos nas embalagens permeáveis, proporcionando maior redução do extrato etéreo, independente da temperatura de armazenamento. No entanto, entre as condições de armazenamento, verificou-se que o rendimento de extrato de etéreo foi menor nas temperaturas de 23 e $10{ }^{\circ} \mathrm{C}$, não diferindo entre si estatisticamente, para o armazenamento em embalagens permeáveis. Para os grãos armazenados em embalagens impermeáveis, observou-se que a temperatura de armazenamento de 10 ${ }^{\circ} \mathrm{C}$ foi favorável, tanto quanto a temperatura de $3{ }^{\circ} \mathrm{C}$, igualando-se estatisticamente os valores de extrato etéreo. Nesta avaliação, a temperatura de armazenamento de $23{ }^{\circ} \mathrm{C}$ foi a que mais afetou o rendimento de extrato etéreo nos grãos de soja (Figura 2). 

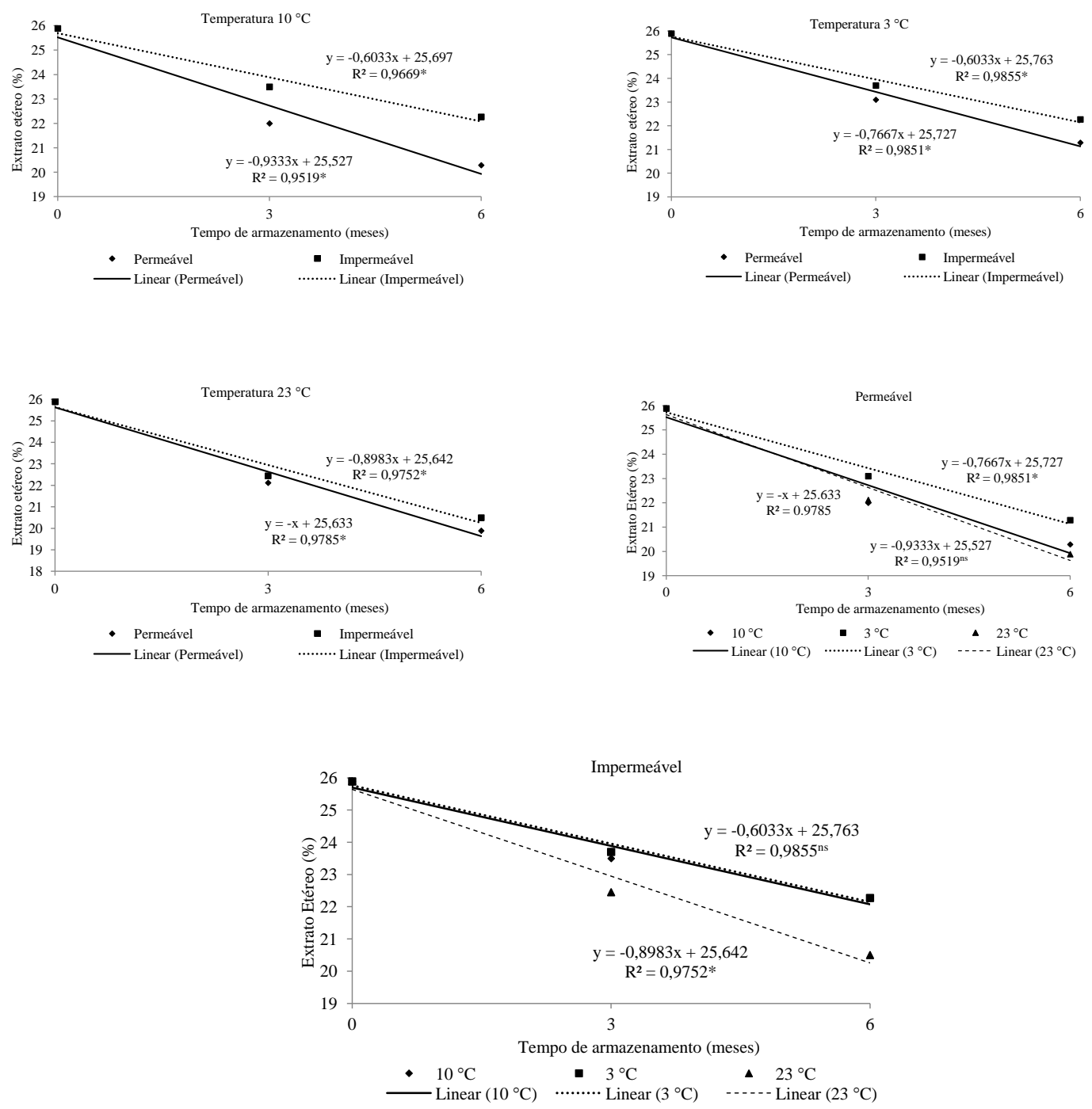

Figura 2. Avaliação da porcentagem de extrato etéreo (\%) em grãos de soja armazenados em diferentes temperaturas do ar e embalagens, ao longo de seis meses. *Significativo $5 \%$ de probabilidade, ${ }^{\text {ns }}$ Não Significativo.

$\mathrm{Na}$ avaliação dos índices de acidez, Figura 3, os resultados indicaram aumento da deterioração dos grãos, aos seis meses de armazenamento, com o aumento da temperatura do ar de armazenamento $(\mathrm{p}<0,05)$. 

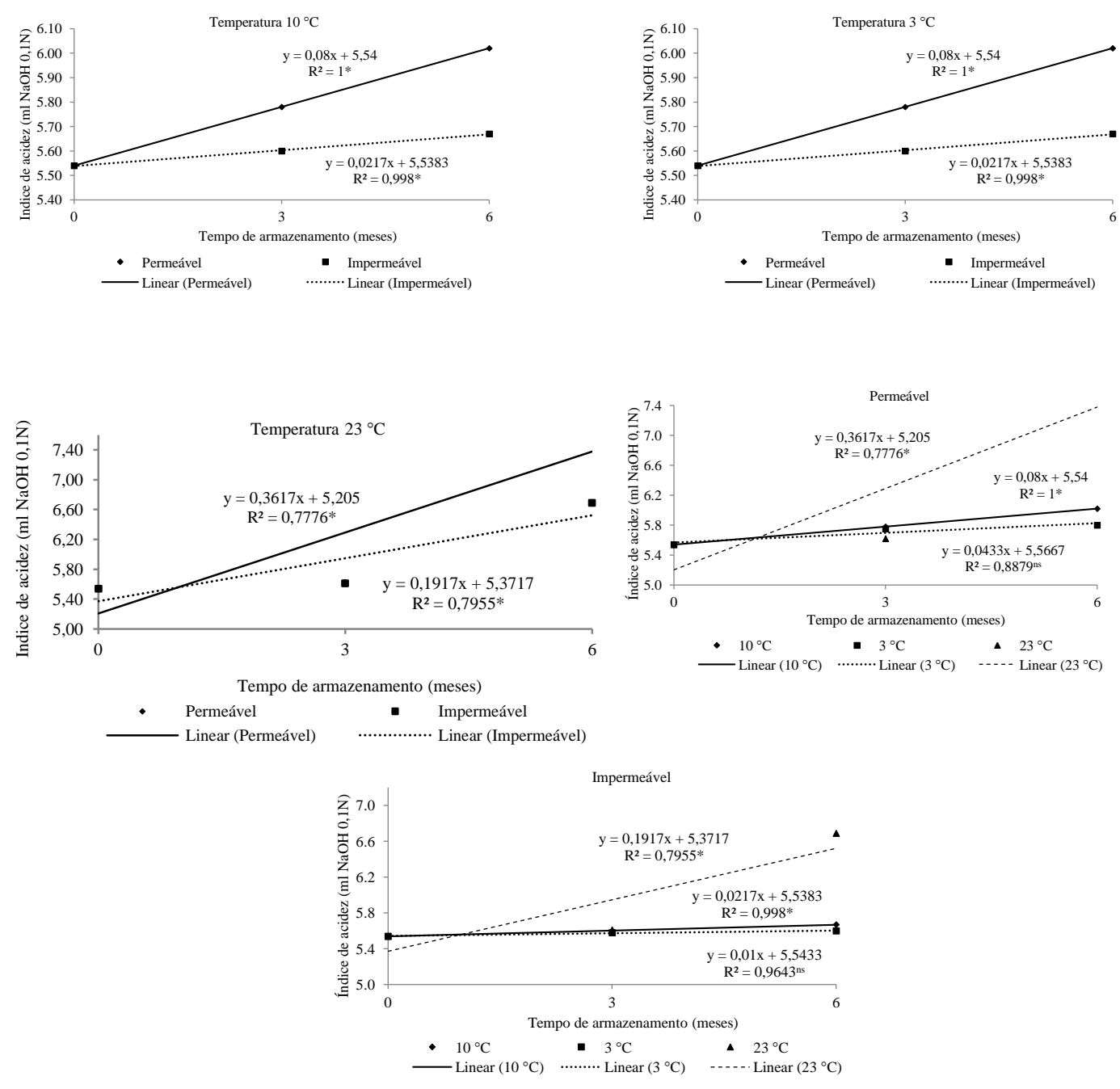

Figura 3. Avaliação do índice de acidez ( $\mathrm{ml} \mathrm{NaOH} 0,1 \mathrm{~N})$ em grãos de soja armazenados em diferentes temperaturas do ar e embalagens, ao longo de seis meses. *Significativo $5 \%$ de probabilidade, ${ }^{\text {ns }}$ Não Significativo.

Os grãos armazenados nas embalagens permeáveis tiveram e na temperatura de $23{ }^{\circ} \mathrm{C}$ tiveram maiores índices de acidez, enquanto que nas temperaturas de 3 e $10{ }^{\circ} \mathrm{C}$ os índices de acidez não tiveram diferenças estatísticas, independente do tipo de embalagem. Em estudo realizado por PARK et al. (2012), relataram aumento no índice de acidez em grãos de soja, para todas as condições de armazenamento, no entanto,o aumento da temperatura e umidade relativa do ar proporcionou maior deterioração dos grãos.
Na Figura 4, pode ser observado, independentemente das condições de armazenamento e embalagem, redução significativa $(\mathrm{p}<0,05)$ na porcentagem de proteína bruta dos grãos, após seis meses de armazenamento. Seguindo as mesmas tendências das outras avaliações de qualidade deste trabalho, verificou-se que, a conservação da porcentagem de proteína bruta dos grãos foi maior para o armazenamento com temperaturas mais baixas e em embalagens impermeáveis $(\mathrm{p}<0,05)$. 

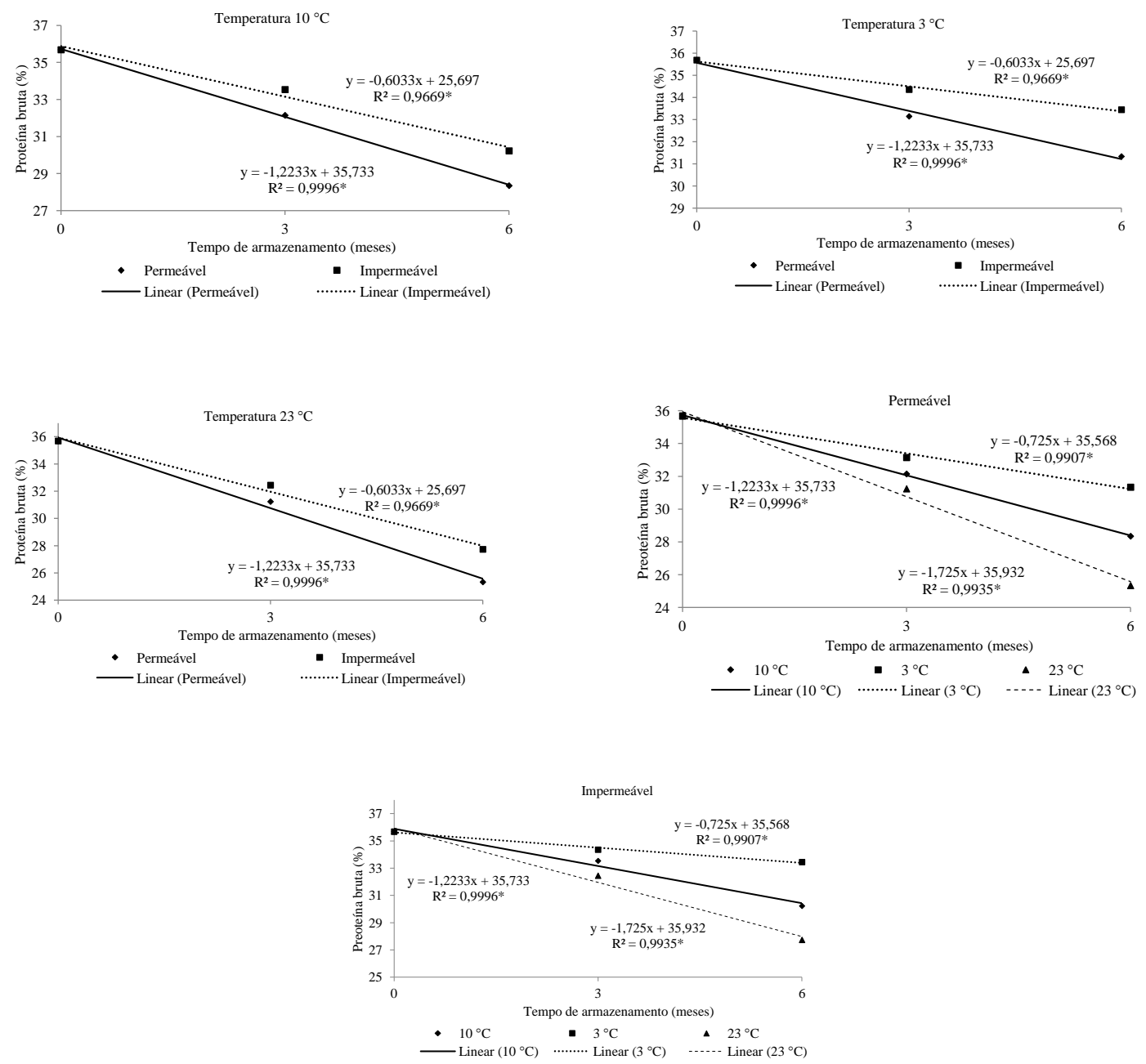

Figura 4. Avaliação da porcentagem de proteína bruta (\%) em grãos de soja armazenados em diferentes temperaturas do ar e embalagens, ao longo de seis meses. *Significativo $5 \%$ de probabilidade, ${ }^{\text {ns }}$ Não Significativo.

As reduções nos teores de proteína bruta durante a armazenagem têm sido relatadas na literatura. LEE \& $\mathrm{CHO}$ (2012), avaliaram o armazenamento de soja durante dois anos, à temperatura ambiente, e observaram redução nos teores de proteína de $43 \%$ para $38,30 \%$ após um ano e de $33,80 \%$ após dois anos de armazenamento. Os resultados com redução nos teores de proteína bruta também foram observados por RANI et al. (2013) em feijão, em diferentes condições de armazenamento. LIU et al. (2008) encontraram resultados semelhantes, com uma redução significativa no teor de roteína de soja na temperatura de armazenamento de $30{ }^{\circ} \mathrm{C}$ e umidade relativa de $88 \%$. Embora as condições de armazenamento influenciaram o teor de proteína bruta nos grãos de soja, o armazenamento em temperaturas mais baixas permitiu que os grãos mantivessem melhor a qualidade o tempo de armazenagem. Segundo RIGUEIRA et al. (2009), a redução da temperatura da massa de grãos, promovendo o resfriamento artificial, é promissor no intuito de manter a qualidade dos grãos, minimizar ou impedir o desenvolvimento de insetospraga e fungos, independentemente das condições climáticas da região. 


\section{CONCLUSÕES}

1) $\mathrm{O}$ resfriamento artificial do ambiente de armazenamento para temperaturas inferiores a $10{ }^{\circ} \mathrm{C}$ pode ser a melhor alternativa para preservar a qualidade dos grãos armazenados.

2) Embalagens impermeabilizadas, para as mesmas condições médias de temperatura e umidade relativa do ar de armazenagem podem contribuir para minimizar perdas em grãos de soja, em comparação com embalagens permeáveis, considerando-se os atributos qualitativos analisados.

\section{AGRADECIMENTOS}

Os autores agradecem a UFMS e a FUNDECT - MS pelo apoio financeiro no desenvolvimento da pesquisa.

\section{REFERÊNCIAS BIBLIOGRÁFICAS}

AOAC. Association of Official Analytical Chemists. Official methods of analysis of the AOAC International. 17th ed. Gaithersburg, 2000.

BRASIL. Ministério da Agricultura, Pecuária e Abastecimento. Regras para análise de sementes. Brasília: Mapa/ACS, 2009, 399p.

BRASIL. Ministério da Agricultura, Pecuária e Abastecimento. Classificação física de grãos de soja. Instrução normativa $\mathrm{n}^{\circ} 11$, de 15 de maio de 2007 , Brasília: Mapa/ACS, 2007.

CARDOSO, R. B. BINOTTI, F. F. da SILVA; CARDOSO, E. D. Potencial fisiológico de sementes de crambe em função de embalagens e armazenamento. Pesquisa Agropecuária Tropical, v. 42(3): 272-278, 2012.

CONAB. Companhia Nacional de Abastecimento, 2015. Disponível em; http://www.conab.gov.br/. Acesso em 25/05/2015.

CORADI, P. C., BORÈM, F. M.; REINATO, C. H. Coffee cherries drying process and the influence of environment relative humidity in the mathematical modeling, moisture content, and enthalpy of vaporization. Energia na Agricultura
(UNESP. Botucatú. CD-Rom), v. 29(2): 148-157, 2014a.

CORADI, P. C.; MELO, E. C.; ROCHA, R. $P$ da. Evaluation of electrical conductivity as a quality parameter of lemongrass leaves (Cymbopogon Citratus Stapf) submitted to drying process. Drying Technology, v. 32(1): 969-980, 2014b.

ELIAS, M. C. Pós-colheita de arroz: secagem, armazenamento e qualidade. 1. ed. Pelotas: Editora e Gráfica Universitária da UFPel, 2009, 24p.

ELIAS, M. C.; OLIVEIRA, M.; SCHIAVON, R. A. Qualidade de arroz na pós-colheita: ciência, tecnologia e normas. Pelotas: Santa Cruz, 2010, 906p.

ALENCAR, E. R.; FARONI, L. R. D.; LACERDA FILHO, A. F.; PETERNELLI, L. A.; COSTA, A. R. Qualidade dos grãos de soja armazenados em diferentes condições. Revista Brasileira de Engenharia Agrícola e Ambiental, v. 13(5): 606-613, 2009.

KONG, F.; CHANG S. K; LIU, Z.; WILSON, L. A. Changes of soybean quality during storage as related to soymilk and tofu making. Journal of Food Science, v. 3(3): 34-144, 2008. 
LACERDA FILHO, A. F.; SOUZA \& SILVA, J.; RESENDE, R. C. Estruturas para armazenagem de grãos. In: SILVA, J. S. (Org.). Secagem e armazenagem de produtos agrícolas. 1 ed. Viçosa: Editora Aprenda Fácil, 2000, p. 325-344.

LEE, J. H.; CHO, K. M. Changes occurring in compositional components of black soybeans maintained at room temperature for different storage periods. Food Chemistry. v. 1(131): 161-169, 2012.

LIU, C.; WANG, X.; MA, H.; ZHANG, Z.; WENRUI, GAO; XIAO, L. Functional properties of protein isolates from soybeans stored under various conditions. Food Chemistry. v. 11(1): 29-37, 2008.

MOSHENIN, N. N. Physical properties of plant and animal materials. New York: Gordon and Breach Publishers, 1986, 841p.

PARK, C. E.; KIM, Y. S.; PARK, K. J.; KIM, B. K. Changes in physicochemical characteristics of rice during storage at different temperatures. Journal of Stored Products Research. v. 48(2): 25-29, 2012.

PEREIRA, W. V. S.; VIEIRA, L. M.; RIBEIRO, L. M.; MERCADANTESIMÕES, M. O.; OLIVEIRA, T. G. S. Armazenamento de sementes de maracujazeiros. Pesquisa Agropecuária Tropical. v. 4(2): 273-278, 2011.

RANI, P. R.; CHELLADURAI, V.; JAYAS, D. S.; WHITE, N. D. G.; KAVITHA-ABIRAMI, C. V. Storage studies on pinto beans under different moisture contents and temperature regimes. Journal of Stored Products Research. v. 52(3): 78-85, 2013.

RIBEIRO, D. M.; CORRÊA, P. C.; RODRIGUES, D. H.; GONELI, A. L. D. Análise da variação das propriedades físicas dos grãos de soja durante o processo de secagem. Boletim da Sociedade Brasileira de Ciência e Tecnologia de
Alimentos, Campinas, v. 1(25): 611-617, 2005.

RIGUEIRA, R. J. H.; LACERDA FILHO, A. F. de; VOLK, M. B. S. Avaliação da qualidade do feijão armazenado em ambiente refrigerado. Alimentos e Nutrição. v. 20(4): 649-655, 2009.

RESENDE, $O$. et al. Modelagem matemática do processo de secagem de duas variedades de feijão (Phaseolus vulgaris L.). Revista Brasileira de Produtos Agroindustriais, Campina Grande, v. 10, n. 1, p. 17-26, 2008.

SMANIOTTO, T. A. S.; RESENDE, O.; MARÇAL, K. A. F.; OLIVEIRA, D. E. C. DE; SIMON, G. A. Qualidade fisiológica das sementes de soja armazenadas em diferentes condições. Revista Brasileira de Engenharia Agrícola e Ambiental, Campina Grande, v. 18(4): 446-453, 2014.

SOARES JUNIOR, M. S.; CALIARI, M.; VERA,R.; SOUZA, A. G. Conservação pós-colheita de mangaba sob refrigeração e modificação da atmosfera de armazenamento. Pesquisa Agropecuária Tropical, v. 38(2): 78-86, 2008.

VIEIRA, R. D.; KRZYZANOWSKI, F. C. Teste de condutividade elétrica. In: KRZYZANOWSKI, F. C.; VIEIRA, R. D.; FRANÇA NETO, J. B. (Eds.). Vigor de sementes: conceitos e testes. Londrina, PR: ABRATES, 1999, Cap.4, p.1-26.

ZIEGLER, V. Efeitos da umidade e da temperatura de armazenamento sobre parâmetros de avaliação da qualidade dos grãos, do óleo e de compostos bioativos de soja. 2014, 110f. Dissertação (Mestrado em Ciência e Tecnologia de alimentos) - Programa de Pós-Graduação em Ciência e Tecnologia de Alimentos. Universidade Federal de Pelotas, Pelotas, 2014. 